\title{
Effect of folic acid on bone metabolism: a randomized double blind clinical trial in postmenopausal osteoporotic women
}

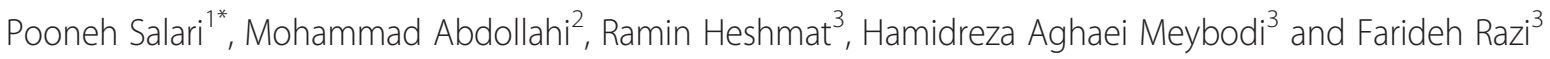

\begin{abstract}
Background: In spite of several studies, the impact of homocysteine level and folic acid supplementation on bone metabolism is yet to be recognized. In this registered clinical trial (IRCT2014042217385N1), we aimed to find out the power of 6-month folic acid supplementation on homocysteine level and bone metabolism.

Methods: Forty postmenopausal osteoporotic women (50 to 87 years) were enrolled in the study. All participants were randomized to receive folic acid $1 \mathrm{mg}(n=17)$ or placebo $(n=14)$. At baseline, 3 months, and finally 6 months post intervention, the level of homocysteine, vitamin B12, and bone biomarkers were measured.

Results: Both groups were similar at baseline. The homocysteine decreased in both groups but statistically non-significant $(P>0.05)$. The changes of the serum level of vitamin B12, osteocalcin, and $\beta$ cross laps were significant between groups after 6 months $(P \leq 0.05)$.

Conclusion: The trend of changes of bone biomarkers after 6 months folic acid supplementation shows that homocysteine concentration and/or folic acid supplementation have impact on the rate of bone metabolism. However, further investigations by larger sample size and differentiating age and gender are still needed to clarify the exact role of folate, homocysteine and vitamin B12.
\end{abstract}

Keywords: Homocysteine, Folic acid, BMD, Bone biomarkers, Osteoporosis, Clinical trial

\section{Introduction}

Osteoporosis, the senile chronic disease is mainly caused by estrogen deficiency, while, environmental and lifestyle factors as well as metabolic and genetic disorders are contributing. As a chronic senile inflammatory disease, it is believed that osteoporosis has common pathophysiological basis with cardiovascular diseases [1]. Hyperhomocysteinemia is considered as an independent risk factor for several chronic senile diseases and conditions including cardiovascular diseases, and Alzheimer disease [2,3]. As the number of devastating consequences in osteoporotic patients is increasing worldwide, determining the possible risk factors and their elimination is crucial. Keeping this in mind, recent studies have shown the possible role of platelets, inflammation, and homocysteine as well as the role of

\footnotetext{
* Correspondence: poonehsalari@gmail.com

${ }^{1}$ Medical Ethics and History of Medicine Research Center, Tehran University of Medical Sciences, 23\# 16 Azar Ave, Keshavarz Blvd, 1417633114 Tehran, Iran
} Full list of author information is available at the end of the article specific medications in the common pathophysiologic pathway of cardiovascular diseases and osteoporosis [4-10]. Accordingly, the role of hyperhomocysteinemia in the pathogenesis of osteoporosis has been considered as a focal point. Serum concentration of homocysteine is inversely related to those of vitamin $\mathrm{B} 12$ and folic acid [11]. From one point during menopause the serum level of homocysteine is increased and from the other point hyperhomocysteinemia is linked with risk of fracture. Folate supplementation may modify the serum concentration of homocysteine, and of greater importance may affect fracture risk, because high homocysteine levels increase the risk of fracture [12]. To our knowledge, there is no enough data about the effect of folate supplementation and homocysteine lowering therapy on bone metabolism and fracture risk. Our previous systematic review showed the possible impact of high homocysteine level on bone quality via induction of osteoclast related bone resorption [3]. With all these in mind, the exact role of homocysteine 
level and folic acid supplementation in regulation of bone metabolism is yet to be elucidated. Based on the implication of bone biomarkers in determination of bone metabolism in osteoporotic patients in a short period of time we aimed to examine the effect of folic acid supplementation on serum level of homocysteine and bone metabolism in postmenopausal osteoporotic women in a randomized, double-blind, placebo-controlled study. For this purpose, we selected key indicators such as bone specific alkaline phosphatase (BALP) from enzymes, osteocalcin (OC) from bone protein markers, $\beta$ cross laps (CTX) and pyridinoline (PYD) from collagenous bone resorption markers to evaluate bone metabolism. All selected bone biomarkers are easily changed within 3-6 months treatment and usually used for monitoring effectiveness of treatment. Furthermore measuring OC and CTX both together is considered as a reasonable choice for evaluating bone degradation and synthesis [13].

\section{Methods}

\section{Subjects}

Forty postmenopausal osteoporotic women who referred to the Diabetes and Metabolic Disorders Clinic were enrolled in the double blind randomized clinical trial. Osteoporosis was diagnosed by the mean of dual energy $\mathrm{X}$-ray absorptimetry $\left(\mathrm{Hologic}^{\circ}\right)$ at femur neck and lumbar vertebrae in all participants. Osteoporosis was defined on the basis of WHO criteria as having BMD $\geq 2.5$ SD below the normal mean for young adult women or T-sore $\leq-2.5$. Participants profile including age, age at menopause, habit of smoking, alcohol consumption, past medical history and use of medications were collected. Participants with a history of cancer, acute infection, endocrinology diseases, taking medications affecting bone metabolism, such as corticosteroids, gonadotropin releasing hormone (GnRH) analogues, anticonvulsant drugs, heparin, aluminum containing antacids, thyroid hormones and anti-osteoporosis medications were excluded (Table 1). The study was

\section{Table 1 Exclusion criteria}

\begin{tabular}{ll}
\hline Exclusion criteria & Medications: \\
\hline Cancer & Corticosteroids \\
Acute infection & Gonadotropin releasing hormone (GnRH) \\
Endocrinologic diseases & medications (bisphosphonates, calcium \\
& and vitamin D, teriparatide, calcitonin, etc) \\
& Anticonvulsants \\
Taking medications & Heparin \\
affecting bone metabolism & Aluminum containing antacids \\
& Thyroid hormones \\
& Selective serotonin reuptake inhibitors (SSRIs)
\end{tabular}

registered in the Iranian Registry of Clinical Trials with the code of IRCT2014042217385N1.

The study was approved by the Ethics Committee of the Endocrinology and Metabolism Research Institute of Tehran University of Medical Sciences. All participants signed the written informed consent after receiving complete information about the study and their contribution.

\section{Experimental design}

All participants were randomly assigned to folic acid or placebo. The patients' assignments were double blind. The method of randomization was simple. Because of few dose-response studies, the most proper dose of folic acid to lower homocysteine concentration is not fully clarified. In a dose-response trial, no significant relation was observed in reduction of homocysteine level when various doses of folic acid were used [8]. Also, the Homocysteine Lowering Trialists Collaboration meta-analysis showed no significant dose-dependent response in the dose range (800-2000 $\mu \mathrm{g} /$ day) of folic acid [14]. Noteworthy, pharmacological doses of folic acid (5 mg/day) may increase the risk of adverse effects [15]. Therefore, present study was designed to administer folic acid at dose of $1 \mathrm{mg} /$ day as a supplement (Figure 1).

Both folic acid and placebo tablets were completely similar in taste, texture and appearance and were produced by Rooz Daru Company (Iran). All participants were asked to inform the clinic in the case of any change in their lifestyle, medication or occurrence of any side effect. Over the study period, in each visit, the patients were asked to feel free to exit from the study if they did not comply with the described protocol.

\section{Laboratory studies}

Blood and urine samples were taken at baseline and after 3 and 6 months. All samples were collected in the early morning and fasting condition. Blood samples were centrifuged at $10000 \times \mathrm{g}$ for $10 \mathrm{~min}$ and kept in the fridge at $-70^{\circ} \mathrm{C}$ until analysis. Serum levels of bone biomarkers including OC, BALP, homocysteine, vitamin B12 and urinary concentrations of PYD and $\beta$ cross laps were measured. Serum OC and $\beta$ cross laps were quantified by N-MID Osteocalcin ELISA and Urine BETA CrossLaps ${ }^{\circ}$ ELISA Immuno Diagnostic Systems (IDS) (Germany), respectively. Urinary PYD and serum level of BALP were measured by MICROVUE PYD EIA ${ }^{\circ}$ and MICROVUE BAP EIA ${ }^{\circ}$ Kits from QUIDEL Corporation (Germany), respectively. Serum level of homocysteine was quantified with enzymatic assay by Axis Shield ${ }^{\circ}$ and serum level of vitamin B12 was measured by the method of chemiluminescence By Diasorin Liaison ${ }^{\circ}$. Intra- and inter-assay coefficients of variation (CV) were $2.2 \%$ and $5.1 \%$ for osteocalcin, $3.9 \%$ and $6.9 \%$ for $\beta$ cross 


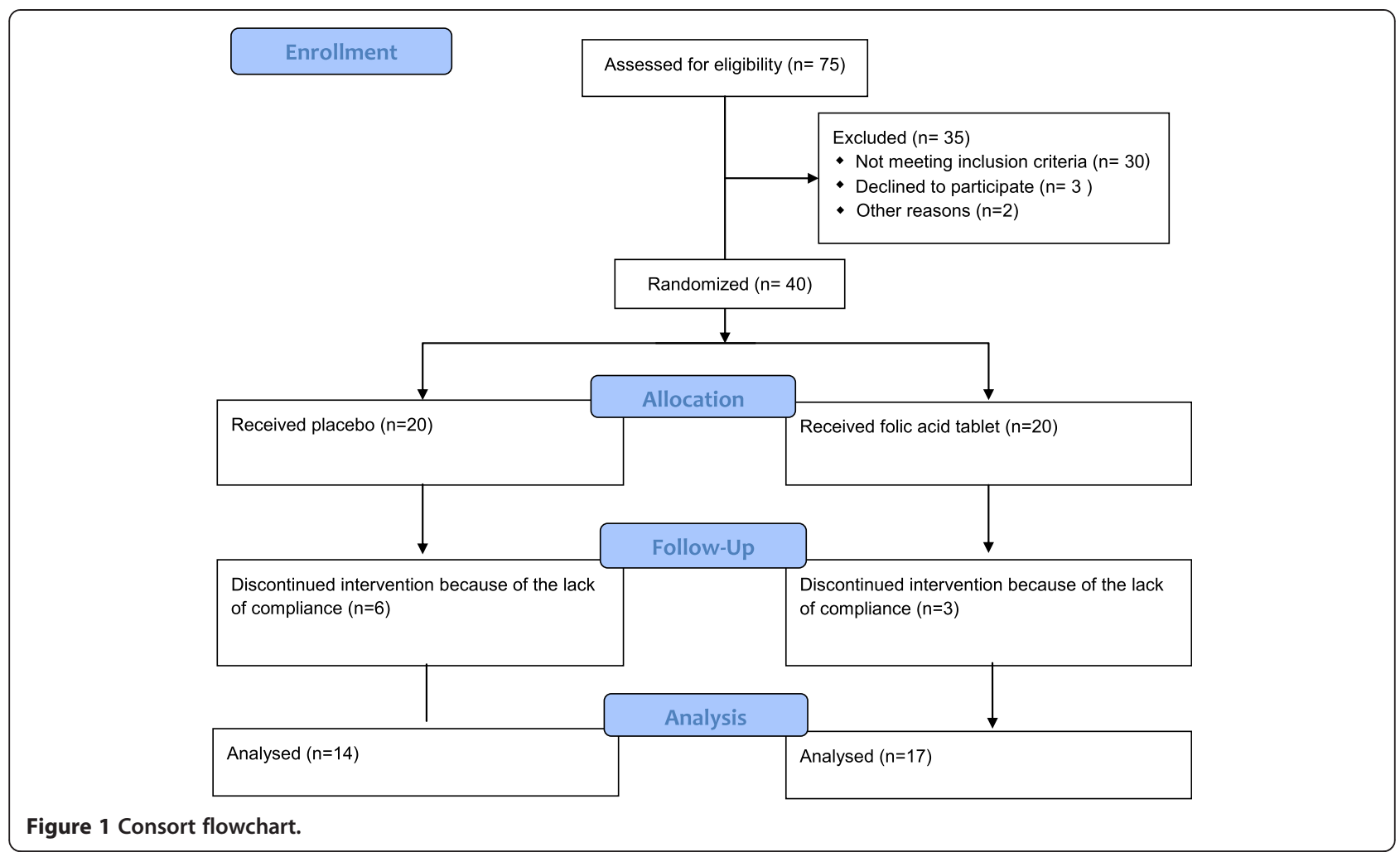

laps, $11.2 \%$ and $9.9 \%$ for PYD, $7.6 \%$ and $5.8 \%$ for BALP, and $4.4 \%$ and $2.2 \%$ for homocysteine.

\section{Statistical analysis}

The StatsDirect version 3.0.117 was used for statistical analysis. Data are expressed as mean \pm SD. Normal distribution of data was confirmed by Kolmogorov-Smirnov test. Baseline values and values after supplementation were compared using T-test. Comparison between groups before and after supplementation was performed using General Linear Model (repeated measure) test. The Pearson correlation test was used for correlations. $P \leq 0.05$ was considered significant.

\section{Results}

The study performed on 40 postmenopausal women, of those 31 participants completed the study (response rate $=77.5 \%)$. Three participants from the treatment group and 6 participants from the control group withdrew the study because of lack of compliance (Figure 1). Table 2 shows the demographic data of all participants. No lifestyle or medication change as well as side effect was recorded. The distribution of data was normal. No statistically significant difference was found between groups at baseline (Table 2). The average baseline homocysteine and vitamin B12 levels were $12.77 \mu \mathrm{mol} / \mathrm{L}$ and $605.72 \mathrm{pg} / \mathrm{ml}$, respectively. The average baseline level of BALP, OC and CTX was $30.5 \mathrm{U} / \mathrm{L}, 15.48 \mathrm{ng} / \mathrm{ml}$, and $2.74(\mu \mathrm{g} / \mathrm{mmol} \mathrm{Cr})$, respectively which were in the normal range. The average baseline urinary PYD level of $43.27(\mu \mathrm{g} / \mathrm{mmol} \mathrm{Cr}$ ) was higher than normal level.

Table 3 presents the biochemical results after supplementation. The serum level of homocysteine decreased in both groups along the study. No significant change was found in each group $(P=0.22$ in treatment group versus $P=0.26$ in the control group) and between groups at 6 months $(P=0.06)$.

In the treatment group, the serum level of vitamin B12 decreased in the first three months followed by an increase after 6 months, while in the control group it decreased during the study period. No significant change in the serum level of vitamin B12 was found in each group $(P=0.189$ and $P=0.173)$. After 6 months serum concentration of vitamin B12 was significantly lower in the control group compared with the treatment group $(P=0.01)$ (Table 3$)$.

The serum level of OC showed a non-significant increase and a decrease in the control group $(P=0.460)$ and treatment groups, respectively $(P=0.384)$. After 6 months, serum level of OC was significantly higher in the control group compared with the treatment group ( $P=0.034$; Table 3$)$.

The serum level of BALP showed a non-significant increase in the treatment $(P=0.614)$ and control $(P=0.326)$ groups. No significant difference was observed between groups after 6 months $(P=0.543$; Table 3$)$. 
Table 2 Demographic data and baseline characteristics of study participants

\begin{tabular}{|c|c|c|c|c|}
\hline & Normal values & Treatment group (17) & Control group (14) & $P$ value \\
\hline Age (yr) & & $63.8 \pm 8.1$ & $64.2 \pm 7.3$ & 0.870 \\
\hline $\mathrm{BMI}\left(\mathrm{kg} / \mathrm{m}^{2}\right)$ & & $25.2 \pm 4.5$ & $26.7 \pm 3.1$ & 0.290 \\
\hline Age at menopause (yr) & & $48.8 \pm 4.6$ & $46.6 \pm 4.7$ & 0.196 \\
\hline Lumbar BMD $\left(\mathrm{g} / \mathrm{cm}^{2}\right)$ & & $0.67 \pm 0.16$ & $0.71 \pm 0.06$ & 0.370 \\
\hline Femoral BMD & & $0.59 \pm 0.07$ & $0.60 \pm 0.06$ & 0.709 \\
\hline Lumbar T-score & & $-3.11 \pm 0.43$ & $-3.01 \pm 0.62$ & 0.615 \\
\hline Femoral T-score & & $-2.32 \pm 0.63$ & $-2.29 \pm 0.46$ & 0.832 \\
\hline Homocysteine ( $\mu \mathrm{mol} / \mathrm{L})$ & $5-20$ & $11.70 \pm 6.63$ & $14.07 \pm 3.60$ & 0.242 \\
\hline Vit B12 (Pg/ml) & $160-970$ & $745.70 \pm 623.07$ & $435.75 \pm 245.25$ & 0.091 \\
\hline $\mathrm{OC}(\mathrm{ng} / \mathrm{ml})$ & $12.8-55.0$ & $15.34 \pm 6.94$ & $15.66 \pm 9.99$ & 0.916 \\
\hline BALP (U/L) & $14.2-42.7$ & $29.94 \pm 11.02$ & $31.17 \pm 11.90$ & 0.767 \\
\hline UPYD ( $\mu \mathrm{g} / \mathrm{mmol} \mathrm{cr})$ & $16.0-37.0$ & $42.99 \pm 11.67$ & $43.61 \pm 11.14$ & 0.882 \\
\hline$U \beta$ cross laps $(\mu \mathrm{g} / \mathrm{mmol} \mathrm{cr})$ & $0.73-7.07$ & $2.45 \pm 1.58$ & $3.10 \pm 1.75$ & 0.285 \\
\hline
\end{tabular}

All data are presented as Mean \pm SD. $\mathrm{Yr}=$ year; $\mathrm{BMI}=$ body mass index; $\mathrm{BMD}=$ bone mineral density; Vit $\mathrm{B} 12=\mathrm{vitamin} \mathrm{B} 12 ; \mathrm{OC}=\mathrm{osteocalcin} ; \mathrm{BALP}=$ bone alkaline phosphatase; UPYD = urine pyridinium cross links; $U \beta$ cross laps $=$ urine $\beta$ cross laps.

The urinary levels of PYD and $\beta$ cross laps nonsignificantly increased in both groups, more prominently in the control group (Table 3). After 6 months, the increase in the level of $\beta$ cross laps in the control group was higher than that of treatment group $(P=0.01)$.

Baseline level of PYD and BALP in the control group was inversely correlated with $\mathrm{BMD}$ and $\mathrm{T}$-score of the lumbar spine $(\mathrm{r}=-0.53, P=0.05)$ and $(\mathrm{r}=-0.59, P=0.02)$, respectively. In the control group, the level of $\beta$ cross laps at baseline and after 6 months showed a negative correlation with BMD and T-score of the lumbar spine $(\mathrm{r}=-0.61, P=0.02)$ and $(\mathrm{r}=-0.61, P=0.01)$, respectively. In addition homocysteine concentration at the end of the study was inversely correlated with BMD and
T-score of femur $(\mathrm{r}=-0.65, P=0.01)$ and $(\mathrm{r}=-61, P=0.01)$, respectively.

\section{Discussion}

In this study we aimed to evaluate the effect of folate supplementation on homocysteine level and bone metabolism in postmenopausal osteoporotic women. In addition we presumed correlations between homocysteine, bone biomarkers and bone specific characteristics including BMD and T score. For this purpose we measured each participant's BMD and T-score of the femur and lumbar spine as well as bone biomarkers. In fact measuring femoral BMD has been considered as the standard of choice for osteoporosis because this site

Table 3 Statistics for serum concentrations of bone biomarkers in both groups in the study period

\begin{tabular}{|c|c|c|c|c|c|c|c|c|}
\hline & \multicolumn{3}{|c|}{ Treatment group $(\mathrm{N}=17)$} & \multirow[t]{2}{*}{$P$ value } & \multicolumn{3}{|c|}{ Control group $(\mathrm{N}=14)$} & \multirow[t]{2}{*}{$P$ value } \\
\hline & Baseline & 3 months & 6 months & & Baseline & 3 months & 6 months & \\
\hline Homocysteine $(\mu \mathrm{mol} / \mathrm{L})$ & $11.70 \pm 6.63$ & $11.52 \pm 4.47$ & $10.17 \pm 4.09$ & 0.226 & $14.07 \pm 3.60$ & $14.50 \pm 4.78$ & $13.21 \pm 4.54$ & 0.266 \\
\hline Cl 95\% & $8.55-14.85$ & $9.40-13.65$ & $8.23-12.12$ & & $12.18-15.96$ & $11.99-17.00$ & $10.83-15.59$ & \\
\hline Vit B12 (Pg/ml) & $745.70 \pm 623.07$ & $517.17 \pm 260.77$ & $655.17 \pm 460.18$ & 0.189 & $435.75 \pm 245.25$ & $375.50 \pm 475.02$ & $235.42 \pm 57.96$ & 0.173 \\
\hline Cl $95 \%$ & $449.51-1041.89$ & $393.21-641.14$ & $436.42-873.94$ & & $307.69-564.23$ & $126.66-624.33$ & $205.70-265.79$ & \\
\hline $\mathrm{OC}(\mathrm{ng} / \mathrm{ml})$ & $15.34 \pm 6.94$ & $14.10 \pm 6.13$ & $13.84 \pm 4.87$ & 0.384 & $15.66 \pm 9.99$ & $16.71 \pm 9.92$ & $17.70 \pm 10.03$ & 0.460 \\
\hline $95 \% \mathrm{Cl}$ & $12.03-18.64$ & $11.18-17.02$ & $11.53-16.16$ & & $10.43-20.90$ & $11.51-21.91$ & $12.44-22.96$ & \\
\hline BALP (U/L) & $29.94 \pm 11.02$ & $30.82 \pm 9.66$ & $31.74 \pm 9.30$ & 0.614 & $31.17 \pm 11.90$ & $32.14 \pm 14.35$ & $34.46 \pm 15.10$ & 0.326 \\
\hline $95 \% \mathrm{Cl}$ & $24.70-35.19$ & $26.23-35.42$ & $27.33-36.17$ & & $24.94-37.41$ & $24.62-39.66$ & $26.55-42.37$ & \\
\hline UPYD ( $\mu \mathrm{g} / \mathrm{mmol} \mathrm{cr})$ & $42.99 \pm 11.67$ & $47.18 \pm 9.99$ & $46.61 \pm 17.60$ & 0.369 & $43.61 \pm 11.14$ & $45.11 \pm 11.04$ & $51.26 \pm 15.56$ & 0.107 \\
\hline $95 \% \mathrm{Cl}$ & $37.44-48.54$ & $42.43-51.93$ & $38.25-54.99$ & & $37.78-49.45$ & $39.32-50.90$ & $43.11-59.41$ & \\
\hline$\cup \beta$ cross laps $(\mu \mathrm{g} / \mathrm{mmol} \mathrm{cr})$ & $2.45 \pm 1.58$ & $2.43 \pm 1.22$ & $2.77 \pm 1.86$ & 0.358 & $3.10 \pm 1.75$ & $3.25 \pm 1.92$ & $3.68 \pm 2.40$ & 0.398 \\
\hline $95 \% \mathrm{Cl}$ & $1.70-3.20$ & $1.85-3.01$ & $1.90-3.66$ & & $2.18-4.03$ & $2.24-4.27$ & $2.42-4.94$ & \\
\hline
\end{tabular}

All data are presented as Mean \pm SD. $\mathrm{Cl}=$ confidence interval; Vit $\mathrm{B} 12=$ vitamin $\mathrm{B} 12 ; \mathrm{OC}=$ osteocalcin; $\mathrm{BALP}=$ bone alkaline phosphatase; UPYD = urine pyridinium cross links; $U \beta$ cross laps $=$ urine $\beta$ cross laps. 
shows the fracture risk similar or higher than that of other sites [16].

Our results showed that supplementation with $1 \mathrm{mg}$ folic acid non-significantly decreases homocysteine level; however reduction of homocysteine in the treatment group was more than control group. According to the Table 1, the mean homocyteine level of all participants at baseline was higher than $10 \mu \mathrm{mol} / \mathrm{L}$ which is a mild elevation [17]. There are several studies which indicate significant homocysteine lowering effect of folic acid in doses $400-800 \mu \mathrm{g}$ per day [18-20]. It is noteworthy to consider that participants of those studies were supplemented with different doses of vitamin B12 $(9-1000 \mu \mathrm{g} /$ day $)$ in addition to folic acid. We suppose that lack of significant effects of folic acid supplementation on homocysteine level is because of mildly elevated values of homocysteine and normal levels of vitamin B12 in both groups at the baseline. Our thought is in agreement with that of Homocysteine Lowering Trialists Collaboration [14]. In addition to serum homocysteine level, folate status may be affected. There is a report that in healthy older adults with normal serum folate level, folic acid supplementation cannot reduce homocysteine level while in those with low serum folate supplementation it may lower homocysteine concentration [21]. It should be noted that in our study and most of other studies, blood samples were taken in the fasting state while a study indicated that about $50 \%$ of participants show hyperhomocysteinemia after methionine load [22]. Therefore it is suggested that fasting blood sample lacks enough sensitivity for measuring serum homocysteine. Likewise racial differences which affect polymorphism of the methylenetetrahydrofolate reductase (MTFHR) gene may affect homocysteine metabolism and should be taken into account in future studies.

In the control group the hemocysteine level at the end of the study was negatively correlated with BMD and T score of femur at baseline $(\mathrm{r}=-0.65, P=0.01)$. Although several studies indicated significant higher levels of homocysteine in osteoporotic women and its inverse relationship with BMD of total femur [23-25] or the risk of fracture [26,27], other investigations did not confirm the association between homocysteine and BMD and/or bone markers $[28,29]$. This is because of a weak correlation between homocysteine and BMD that failed to be detected in small sample size. A dose-response relationship between homocysteine concentration and bone loss in men and premenopausal women has been reported [30]. In a casecontrol study in the Women's Health Initiative Observational Study, the modest association of high homocysteine levels with increased risk of hip fracture was found [12]. On the other hand, a high level of homocysteine or low level of vitamin B12 and folate were not found as the risk factors of vertebral fractures in postmenopausal women. However, the relationship between levels of homocysteine and vitamin B12 and low BMD was recognized [31]. In a cohort study, association of high homocysteine concentration and higher bone loss over 4 years in postmenopausal women was found [32].

Our data showed significant difference in the serum level of vitamin B12 after 6 months and its serum level was significantly lower in the control group at the end of the study $(P=0.01)$.

Vitamin B12 acts as a cofactor for transformation of homocysteine to methionine. So both folic acid and vitamin B12 may reduce serum homocysteine. Vitamin B12 seems to be involved in osteoblast activity and formation of bone [33], and inhibits osteoclast function [34]; however, the exact mechanism of vitamin B12 in influencing bone density is not fully understood.

According to the Framingham Osteoporosis Study, serum level of vitamin B12 less than $250 \mathrm{pg} / \mathrm{ml}$ is considered as vitamin B12 deficiency and is associated with lower BMD [35]. The participants in our study had normal serum level of vitamin B12 and after 6 months its mean interestingly reached $233.45 \mathrm{pg} / \mathrm{ml}$ in the control group.

We found no correlation between vitamin B12 and bone markers or BMD which is in agreement with other study which showed no relationship between vitamin B12 supplementation and level of BALP in Mexican women [36].

It was found that vitamin B12 and folate are correlated with BMD in postmenopausal women and the possibility of involvement of a mechanistic link was suggested [37].

We observed non-significant increase and decrease in the level of OC in the control and treatment groups, respectively; however we found a significant difference between groups. To date no study has evaluated the pattern of alteration of $\mathrm{OC}$ in relation to homocysteine.

The level of BALP over the study period showed nonsignificant increase in both groups, more profoundly in the control group.

Homocysteine interacts with lysyl oxidase in collagen post-translational modifications and cross linking. Therefore it influences formation of the cross-link [38]. In addition to bone formation markers, bone resorption markers including PYD and $\beta$ cross laps were assessed in the present study. Our results showed parallel nonsignificant increase in the levels of both PYD and $\beta$ cross laps in both groups. Furthermore the level of $\beta$ cross laps was significantly higher in the control group. According to the higher level of all measured bone biomarkers in the control group after 6 months, it is suggested that folic acid supplementation reduces serum level of homocysteine which follows by suppression of bone metabolism. However because of small sample size, the power of our study does not permit to prove our hypothesis. Not only our study but also studies with longer duration up to 2 years could not show a significant effect of folic acid supplementation on bone markers [34,39]. Despite a 
significant reduction of homocysteine levels with folic acid and vitamin B12 supplementation, no significant impact of vitamin B supplementation on bone markers was found in another study while the final level of CTX and alkaline phosphatase was higher in the control group [17]. In contrast, a study reported a strong correlation between homocysteine and serum c-terminal telopeptide (CTx) levels [40]. The results of a recent longitudinal study showed a positive correlation between homocysteine and total alkaline phosphatase. It was concluded that increase in BALP after hyperhomocysteinemia is the result of induction of bone regeneration after bone resorption [29]. Those results may support our results from this point of view.

Regarding the small sample size and enrolment of patients from one referral center limits extrapolation of the results of the study. Although we asked the participants to follow their routine lifestyle in the study period, our information about their lifestyle is lacking. Noteworthy to consider, all of the participants had mildly elevated serum level of homocysteine which may affect their response to supplementation; also none of the participants were taking calcium and/or vitamin $\mathrm{D}$ or other type of supplement.

Our study presents that level of all of the biochemical bone markers showed the highest increase in the control group versus the treatment group in the study period and the changes in $\mathrm{OC}$, and $\beta$ cross laps were significant between groups. Our hypothesis is that serum level of homocysteine, folate supplementation and serum level of vitamin B12 may have a preventive effect on bone metabolism and inversely affect bone metabolism and its rate, however because of the limited sample size, the potency of our study is not enough to be extrapolated. Therefore further investigations about the impact of folic acid supplementation on the rate of bone metabolism in men and women from different ages with larger sample size is highly recommended.

\section{Competing interests}

The authors declare that they have no competing interests.

\section{Authors' contribution}

PS: Study design, preparing the medication, performing the study, statistical analysis and drafting the manuscript; MA: Contribution in study design, performing the study, revising the manuscript; $\mathrm{RH}$ : Collaboration in performing the study, statistical analysis and revising the manuscript; HRAM: Contribution in study design, performing the study and revising the draft; FR: Laboratory analysis and revision of the draft. All authors read and approved the final manuscript.

\section{Acknowledgement}

The research project financially supported by Endocrinology and Metabolism Research Institute and Diabetic Research Center of Tehran University of Medical Sciences and the authors would like to thank them. Also the authors would like to thank Dr Keshtkar, Miss Shirazi and Dr Ghorbani for their great help and assistance. Also we gratitude all study participants.

\section{Author details}

Medical Ethics and History of Medicine Research Center, Tehran University of Medical Sciences, 23\# 16 Azar Ave, Keshavarz Blvd, 1417633114 Tehran, Iran. ${ }^{2}$ Faculty of Pharmacy and Pharmaceutical Sciences Research Center, Tehran University of Medical Sciences, Tehran, Iran. ${ }^{3}$ Endocrinology and Metabolism Research Institute, Tehran University of Medical Sciences, Tehran, Iran.

Received: 21 June 2014 Accepted: 2 September 2014

Published online: 16 September 2014

\section{References}

1. Salari P, Abdollahi M: A comprehensive review of the shared roles of inflammatory cytokines in osteoporosis and cardiovascular diseases as two common old people problem: actions toward development of new drugs. Int J Pharmacol 2011, 7(5):552-567.

2. Wald DS, Law M, Morris JK: Homocysteine and cardiovascular disease: evidence on causality from a meta-analysis. Br Med J 2002, 325:1202-1206.

3. Seshadri S, Beiser A, Selhub J, Jacques PF, Rosenberg IH, D'Agostino RB, Wilson PW, Wolf PA: Plasma homocysteine as a risk factor for dementia and Alzheimer's disease. N Engl J Med 2002, 346:476-483.

4. Salari P, Abdollahi M: Association of hyperhomocysteinemia with osteoporosis: a systematic review. Therapy 2008, 5(2):215-222.

5. Salari $P$, Abdollahi M: The role of platelets in bone remodeling. Inflamm Allergy Drug Target 2010, 9:393-399.

6. Salari $P$, Abdollahi M: Controversial effects of non-steroidal anti-inflammatory drugs on bone: a review. Inflamm Allergy Drug Target 2009, 8:169-175.

7. Salari Sharif $P$, Asalforoush M, Ameri F, Larijani B, Abdollahi M: The effect of $\mathrm{n}-3$ fatty acids on bone biomarkers in Iranian postmenopausal osteoporotic women: a randomized clinical trial. AGE 2010, 32:179-186.

8. Salari Sharif P, Abdollahi M: A systematic review on the relation between use of statins and osteoporosis. Int J Pharmacol 2011, 7(2):180-188.

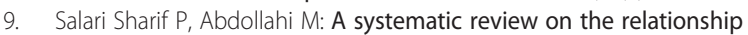
between $\beta$-blockers and bone health. Int J Pharmacol 2010, 6(5):577-583.

10. Abdollahi $M$, Larijani $B$, Rahimi $R$, Salari $P$ : Role of oxidative stress in osteoporosis. Therapy 2005, 2(5):787-796.

11. Brattstrom L: Vitamins as homocysteine-lowering agents. J Nutr 1996, 126:S1276-S1280.

12. LeBoff MS, Narweker R, LaCroix A, Wu L, Jackson R, Lee J, Bauer DC, Cauley J, Kooperberg C, Lewis C, Thomas AM, Cummings S: Homocysteine levels and risk of hip fracture in postmenopausal women. J Clin Endocrinol Metab 2009, 94:1207-1213.

13. Leeming DJ, Alexandersen $P$, Karsdal MA, Qvist P, Schaller S, Tankó LB: An update on biomarkers of bone turnover and their utility in biomedical research and clinical practice. Eur J Clin Pharmacol 2006, 62:781-792.

14. Homocysteine Lowering Trialists Collaboration: Lowering blood homocysteine with folic acid based supplements: meta-analysis of randomized trials. BMJ 1998, 316:894-898.

15. Van Wijngaarden JP, Dhonukshe-Rutten RA, Van Schoor NM, van der Velde N, Swart KM, Enneman AW, Van Dijk SC, Brouwer-Brolsma EM, Zilikens MC, Van Meurs JB, Brug J, Uitterlinden AG, Lips P, De Groot LC: Rationale and design of the B-PROOF study, a randomized controlled trial on the effect of supplemental intake of vitamin B12 and folic acid on fracture incidence. BMC Geriatric 2011, 11:80.

16. Kanis JA, McCloskey EV, Johansson H, Oden A, Melton LJ III, Khaltaev N: A reference standard for the description of osteoporosis. Bone 2008, 42:467-475

17. Jacques PF, Selhub J, Bostom AG, Wilson PWF, Rosenberg $\mathbb{H}$ : The effect of folic acid fortification on plasma folate and total homocysteine concentrations. N Engl J Med 1999, 340:1449-1454.

18. Keser I, Ilich JZ, Vrkic N, Giljevic Z, Colic Baric I: Folic acid and vitamin B12 supplementation lowers plasma homocysteine but has no effect on serum bone turnover markers in elderly women: a randomized, double-blind, placebo-controlled trial. Nutr Res 2013, 33:211-219.

19. Wolters M, Hermann S, Hahn A: Effect of multivitamin supplementation on the homocysteine and methylmalonic acid blood concentrations in women over the age of 60 years. Eur J Nutr 2005, 44:183-192.

20. Lewerin C, Nilsson-Ehle H, Matousek M, Lindstedi G, Steen B: Reduction of plasma homocysteine and serum methylmalonate concenttrations in apparently healthy elderly subjects after treatment with folic acid vitamin B12 and vitamin B6: a randomized trial. Eur J Clin Nutr 2003, 57:1426-1436. 
21. Anderson CAM, Jee SH, Charleston J, Narrett M, Appel LJ: Effects of folic acid supplementation on serum folate and plasma homocysteine concentrations in older adults: a dose-response trial. Am J Epidemiol 2010, 172:932-941.

22. Van der Driend R, Biesma DH, Banga JD: Postmethionine-load homocysteine determination for the diagnosis of hyperhomocysteinemia and efficacy of homocysteine lowering treatment regimens. Vasc Med 2001, 7:29-33.

23. Bozkurt N, Erdem M, Yilmaz E, Erdem A, Biri A, Kubatova A, Bozkurt M: The relationship of homocysteine $B 12$ and folic acid with the bone mineral density of the femur and lumbar spine in Turkish postmenopausal women. Arch Gynecol Obstet 2009, 280:381-387.

24. Bucciarelli P, Martini G, Martinelli I, Ceccarelli E, Gennari L: The relationship between plasma homocysteine levels and bone mineral density in post-menopausal women. European J Intern Med 2010, 21:301-305.

25. Kuyumcu ME, Yesil Y, Oztürk ZA, Cınar E, Kızılarslanoglu C, Halil M, Ulger Z, Yesil NK, Cankurtaran M, Anoğul S: The association between homocysteine (hcy) and serum natural antioxidants in elderly bone mineral densitometry (BMD). Arch Gerontol Geriatr 2012, 55:739-743.

26. Van Meurs JB, Dhonukshe-Rutten RA, Pluijm SM, van der Klift M, De Jonge R, Lindemans J, De Groot LC, Hofman A, Witteman JC, Van Leeuwen JP, Breteler MM, Lips P, Pols HA, Uitterlinden AG: Homocysteine levels and the risk of osteoporotic fracture. N Eng J Med 2004, 350:2033-2041.

27. McLean RR, Jacques PF, Selhub J, Tucker KL, Samelson EJ, Broe KE, Hannan MT, Cupples LA, Kiel DP: Homocysteine as a predictive factor for hip fracture in older persons. N Eng J Med 2004, 350:2042-2049.

28. Holstein JH, Herrmann M, Splett C, Hermann W, Garcia P, Histing T, Klein M, Kurz K, Siebel T, Pohlemann T, Menger MD: Hyper homocysteinemia is not associated with reduced bone quality in humans with hip osteoarthritis. Clin Chem Lab Med 2010, 48:821-827.

29. Rumbak I, Zizic V, Sokolić L, Cvijetićc S, Kajfež R, Barić IC: Bone mineral density is not associated with homocysteine level, folate and vitamin B12 status. Arch Gyneol Obstet 2012, 285:991-1000.

30. Kim BJ, Koh JM, Ahn SH, Lee SH, Kim EH, Bae SJ, Kim HK, Choe JW, Lim KH, Pyun KH, Kim TH, Kim SY, Kim GS: High serum total homocysteine levels accelerates hip bone loss in healthy premenopausal women and men. Bone 2013, 52:56-62.

31. Maghraoui AE, Ghozlani I, Mounach A, Rezqi A, Oumghar K, Achemlal L, Bezza A, Ouzzif Z: Homocysteine folate and vitamin B12 levels and vertebral fracture risk in postmenopausal women. J Clin Densitometr 2012, 15:328-333.

32. Zhu K, Beilby J, Dick IM, Devine A, Soós M: The effects of homocysteine and MTHFR genotype on hip bone loss and fracture risk in elderly women. Osteoporos Int 2009, 20:1183-1191.

33. Kim GS, Kim CH, Park JY, Lee KU, Park CS: Effects of vitamin B12 on cell proliferation and cellular alkaline phosphatase activity in human bone marrow stromal osteoprogenitor cells and UMR106 osteoblastic cells. Metabolism 1996, 45:1443-1446.

34. Herrmann M, Schmist J, Umanskaya N, Colaianni G, Al Marrawi F, Widmann T, Zallone A, Wildemann B, Herrmann W: Stimulation of osteoclast activity by low B-vitamin concentrations. Bone 2007, 41:584-591.

35. Tucker KL, Hannan MT, Qiao N, Jacques PF, Selhub J, Cupples LA, Kiel DP: Low plasma vitamin B12 associated with lower bone mineral density: the Framingham osteoporosis study. J Bone Miner Res 2005, 20:152-158

36. Shahab-Ferdows $\mathrm{S}$, Anaya-Loyola MA, Vergara-Castaňeda H, Rosado JL, Keyes WR, Newman JW, Miller JW, Allen LH: Vitamin B-12 supplementation of rural Mexican women changes biochemical vitamin B-12 status indicators but does not affect hematology or a bone turnover marker. J Nutr 2012, 142:1881-1887.

37. Haliloglu B, Aksungar FB, Ilter E, Peker H, Akm FT, Ozekier U: Relationship between bone mineral density bone turnover markers and homocysteine folate and vitamin B12 levels in postmenopausal women. Arch Gynecol Obstet 2010, 281:663-668.

38. Liu G, Nellaiappan K, Kagan HM: Irreversible inhibition of lysyl oxidase by homocysteine thiolactone and its selenium and oxygen analogues. Implications for homocystinuria. J Biol Chem 1997, 272:32370-32377.

39. Herrmann M, Umanskaya N, Traber L, Schmidt-Gayk H, Menke W, Lanzer G, Lenhart M, Peter Schmidt J, Herrmann W: The effect of B-vitamins on biochemical bone turnover markers and bone mineral density in osteoporotic patients: a 1-year double blind placebo controlled trial Clin Chem Lab Med 2007, 45:1785-1792.

40. Gerdhem P, Iwaska KK, Isakkson A, Pettersson K, Väänänen HK, Obrant KJ Akesson K: Associations between homocysteine bone turnover BMD mortality and fracture risk in elderly women. J Bone Miner Res 2007, 22:127-134.

doi:10.1186/s40199-014-0062-9

Cite this article as: Salari et al:: Effect of folic acid on bone metabolism: a randomized double blind clinical trial in postmenopausal osteoporotic women. DARU Journal of Pharmaceutical Sciences 2014 22:62.

\section{Submit your next manuscript to BioMed Central and take full advantage of:}

- Convenient online submission

- Thorough peer review

- No space constraints or color figure charges

- Immediate publication on acceptance

- Inclusion in PubMed, CAS, Scopus and Google Scholar

- Research which is freely available for redistribution

Submit your manuscript at www.biomedcentral.com/submit
C) Biomed Central 